\title{
Author Spotlight: Jasleen K. Grewal
}

\author{
Jasleen K. Grewal ${ }^{1}$
}

Published online: 16 July 2020

(c) Springer Science+Business Media, LLC, part of Springer Nature 2020

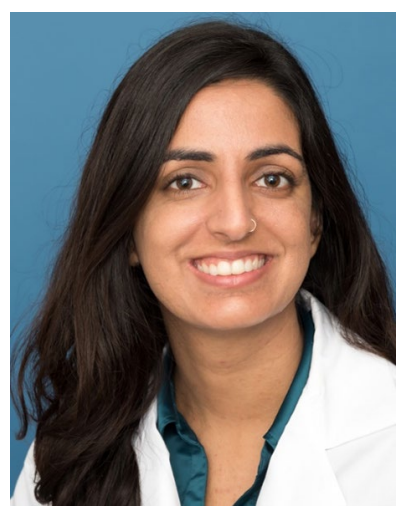

California, Irvine. She will spend the third year of her fellowship focusing on small bowel diseases in order to develop expertise in managing small bowel pathology, reading capsule endoscopy, and performing deep enteroscopy. Her interest in patients with complex clinical presentations across the spectrum of gastroenterology and hepatology arises from the diagnostic challenges that these patients pose that in turn increase the maturity and knowledge of their caregivers. She hopes to be able through careful and thoughtful analysis of patient data to arrive at the correct diagnosis in order to optimize patient management and consequently hone her skills as a clinician, so that she may better serve future patients in their hour of need.

Jasleen K. Grewal is a second-year Gastroenterology fellow at University of California, Los Angeles (UCLA). She completed her MD at Ohio State University and her Internal Medicine and Chief Residency training at University of

Publisher's Note Springer Nature remains neutral with regard to jurisdictional claims in published maps and institutional affiliations.

Jasleen K. Grewal

JGrewal@mednet.ucla.edu

1 University of California, Los Angeles, Los Angeles, USA 